\title{
Perspectives on BIM Profession of BIM Specialists and non-BIM Specialists: Case Study in Vietnam
}

\author{
Ngoc Quyet Le ${ }^{1}$, Michael Er ${ }^{2}$, Shankar Sankaran ${ }^{3}$ and Ngoc Binh Ta ${ }^{4}$ \\ 1,2,3 University of Technology Sydney, NSW 2007, Australia \\ ${ }^{4}$ Institute of Construction Economics, Hanoi, Vietnam
}

\begin{abstract}
The adoption of Building Information Modelling (BIM) has been recently increasing within the Architecture, Engineering and Construction (AEC) industry. The current approach on adoption of BIM by the Vietnamese decision makers (e.g. government agencies and senior industry leaders) is primarily concerned with improving the adoption rate measured by the speed of diffusion and the number of adopters at basic implementation level such as 3D functions. This paper explores a different perspective on BIM adoption in Vietnam which has been neglected by proposing that the efforts of the decision makers should shift into regulatory supports and diffusion networks facilitating higher levels of BIM implementation such as 4D construction scheduling, 5D cost estimating etc. to confirm their long-term commitment to advanced BIM practices. Twenty-nine participants including BIM specialists and non-BIM specialists were selected from seven AEC organizations. Semi-structured interviews were employed for data collection. Key findings revealed general perceptions of the BIM profession such as "job insecurity", "depleted motivation", "BIM as supporting roles" and "BIM as new skill sets". Recommendations for programs supporting BIM adoption are also discussed.
\end{abstract}

Keywords: BIM Adoption, BIM Profession, BIM Specialists, non-BIM Specialists, Qualitative Case Study, Developing Countries, Vietnam

\section{Introduction: Review of BIM Adoption in Vietnam}

The AEC industry by its nature of complexity (e.g. multidisciplinary working environment) has suffered from high fragmentation, poor productivity, cost and time overruns as well as enduring conflicts and disputes. BIM as an integrated information system, therefore, promises to address these problems. However, the use of BIM has not had the expected impact on the construction industry in most developing countries as compared to developed countries even though it has been introduced a decade ago [1]. Particularly in Vietnam, BIM has been reportedly being in use since 2009 [2] but 3D coordination and 2D drawing extraction still are the most used applications among AEC stakeholders [3]. Recent BIM studies in Vietnam showed that 3D designs alone, despite their wide range usage, has not significantly changed the AEC industry from traditional 2D CAD projects (i.e. linear platform) to BIM-based projects (i.e. collaborative platform) as expected [2], [3]. Diffusion of Innovation Theory (DOIT) has been widely 
used to interpret why an individual either decides to make full use of an innovation as the best course of action available (adoption), or choose not to adopt it (rejection) [4]. However, the phenomenon of "retaining the adoption of innovation [BIM] but being limited into small scale (e.g. pilot projects) and low level of implementation (e.g. 3D designs) for a long time" found in Vietnam [2], [3] is relatively unexplored in DOIT.

With the aim of contributing to DOIT and its relevance to BIM adoption, this paper focuses on the perspectives on BIM profession of BIM specialists and non-BIM specialists to understand why Vietnamese AEC professionals hold BIM back to be applied to 3D designs. Further, the Government mandatory submission of 3D models for all first-class projects and public projects by 2020 [5]; and the organizational strategy focusing on extensive in-house equipment of 3D tools are likely not adequate for changing the sluggish adoption in Vietnam [2]. This is because BIM model itself is not a goal, but rather a mean by which project goals may be achieved [6]. The truly successful $\mathrm{BIM}$ is related to sociology (e.g. communication and collaboration) rather than BIM technology update. Therefore, diffusion networks (e.g. professional network for BIM) and regulatory supports (e.g. the national recognition of BIM professionals) could be more important to ensure industry engagement with BIM at national level. This issue will be discussed as a recommendation for policy makers and senior industry managers.

\section{Methodology}

Qualitative case study was employed as it allows for multiple facets of the phenomenon to be revealed and understood; particularly when there is less research on BIM adoption regarding Vietnamese context [7]. Respondents were identified through a snowball sampling technique which is based on referrals from initial respondents to generate additional respondents. This technique could help the researchers to collect primary data in a time and cost-effective manner. Respondents' profiles are coded to protect their anonymity (see Table 1). The findings will be discussed using DOIT (See Section 4).

Table 1. Respondents' profiles

\begin{tabular}{llll}
\hline Company & Respondent & Position & BIM role \\
\hline \multirow{2}{*}{$\mathrm{D}_{1}$ (Design) } & $\mathrm{R}_{1} \mathrm{D}_{1} ; \mathrm{R}_{2} \mathrm{D}_{1}$ & Director Board & Non- BIM Specialist \\
& $\mathrm{R}_{3} \mathrm{D}_{1} ; \mathrm{R}_{4} \mathrm{D}_{1} ; \mathrm{R}_{5} \mathrm{D}_{1}$ & Design Leader & BIM Specialists \\
& $\mathrm{R}_{6} \mathrm{D}_{1} ; \mathrm{R}_{7} \mathrm{D}_{1} ; \mathrm{R}_{8} \mathrm{D}_{1}$ & Drafter & BIM Specialists \\
\hline $\mathrm{D}_{2}$ (Design) & $\mathrm{R}_{1} \mathrm{D}_{2}$ & Director Board & Non- BIM Specialist \\
\hline $\mathrm{D}_{3}$ (Design) & $\mathrm{R}_{1} \mathrm{D}_{3}$ & BIM Manager & BIM Specialists \\
\hline $\mathrm{D}_{4}$ (Design) & $\mathrm{R}_{1} \mathrm{D}_{4}$ & Director Board & Non- BIM Specialist \\
\hline & $\mathrm{R}_{1} \mathrm{C}_{1}$ & BIM Manager & BIM Specialist \\
$\mathrm{C}_{1}$ (Contractor) & $\mathrm{R}_{2} \mathrm{C}_{1} ; \mathrm{R}_{3} \mathrm{C}_{1} ; \mathrm{R}_{4} \mathrm{C}_{1}$ & Site Manager & Non- BIM Specialist \\
& $\mathrm{R}_{5-10} \mathrm{C}_{1}$ & BIM coordinator & BIM Specialist \\
& $\mathrm{R}_{11-15} \mathrm{C}_{1}$ & Site Engineer & Non- BIM Specialist \\
\hline $\mathrm{O}_{1}$ (Owner) & $\mathrm{R}_{1} \mathrm{O}_{1}$ & BIM Manager & BIM Specialist \\
\hline $\mathrm{G}_{1}$ (Government Agency) & $\mathrm{R}_{1} \mathrm{G}_{1} ; \mathrm{R}_{2} \mathrm{G}_{1}$ & Change Agent & Non- BIM Specialist \\
\hline
\end{tabular}

Total: 07 organizations with 29 respondents (15 BIM specialists and 14 non-BIM specialists) 


\section{$3 \quad$ Findings}

\subsection{Theme 1: Self-recognition of BIM profession in AEC firms}

Job Insecurity. Firstly, BIM specialists indicated their welfare concern arising from the copyright liability of BIM software. "Copyright liability can make BIM team stop working until all related legal issues are resolved." $-\mathrm{R}_{3} \mathrm{D}_{1} ; \mathrm{R}_{4} \mathrm{D}_{1} ; \mathrm{R}_{1} \mathrm{D}_{3}$. Most of respondents admitted illegal BIM programs have been used in their workplace, thus, raising the risk of financial and reputational damage. "Penalties for infringement could damage organizational finance and affect employees' wages." $-\mathrm{R}_{3} \mathrm{D}_{1} ; \mathrm{R}_{4} \mathrm{D}_{1} ; \mathrm{R}_{1} \mathrm{D}_{3}$. Secondly, majority of BIM specialists acknowledged that their products are deficient and, thus, perceived inadequate to assure their BIM roles within the company, not to mention construction industry. "We can't guarantee our position in company with imperfect BIM products."- $\mathrm{R}_{3} \mathrm{D}_{1} ; \mathrm{R}_{4} \mathrm{D}_{1} ; \mathrm{R}_{1} \mathrm{C}_{1} ; \mathrm{R}_{5-10} \mathrm{C}_{1}$. This is because purchasing $\mathrm{BIM}$ authoring packages can represent a significant overhead for construction companies; whereas a small number of licensed software is not adequate for the large project's demands.

Depleted Motivation. Most of BIM specialists conceded their poor morale when constantly working in a trial or pilot environment. This mechanism does not offer an opportunity for BIM specialists, especially young staffs, to acquire practical experiences - making them feel unenthusiastic and anxious about their skill erosion. "Every day working around pilot projects and trial experiments frustrate us." $-\mathrm{R}_{1} \mathrm{C}_{1} ; \mathrm{R}_{5-10} \mathrm{C}_{1}$. Additionally, BIM specialists found their career path disadvantaged in comparison with peers using AutoCAD. Particularly, in the same period of time working, AutoCAD users could accumulate sufficient experiences from real projects- qualified by the number and size of completed projects, to gain promotion or achieve professional certificates. Conversely, BIM adopters only carry out pilot projects (i.e. being inadequately recognized in professional profiles) and the scope of work is limited in large-long duration project (i.e. being slowly updated in professional profiles). "Our career path is ambiguous and lag behind CAD users." $-\mathrm{R}_{1} \mathrm{C}_{1} ; \mathrm{R}_{5-10} \mathrm{C}_{1}$. Finally, the feeling of isolation an emerging BIM profession would possibly discourage BIM adopters from pursuing higher level of BIM implementation. "We feel lonely in new BIM profession as the connection to BIM fellows and experts is lacking. "- $\mathrm{R}_{3} \mathrm{D}_{1} ; \mathrm{R}_{4} \mathrm{D}_{1} ; \mathrm{R}_{5} \mathrm{D}_{1} ; \mathrm{R}_{1} \mathrm{C}_{1} ; \mathrm{R}_{5-10} \mathrm{C}_{1}$. The lack of "diffusion networks" is likely the main reason. BIM specialists stated that it is impossible for them to raise questions of BIM applications or report a software crash to any official support (e.g. BIM knowledge network) because the administrators could track the software licenses back and find their violation. Moreover, it appears that young BIM staffs get little guidance from senior managers regarding proper BIM implementation in daily tasks. This is because older people proficient in AEC speciality tend to lack in BIM technical skills whereas young people with better technology competence are short of discipline specific skills [3].

\subsection{Theme 2: Social-recognition of BIM profession in AEC business}

BIM profession as a supporting role. Most non-BIM specialists at high level management described BIM as a supporter for project deliverables. For example, " $3 D$ representation becomes popular in visual marketing strategy and technical meeting with stakeholders." $-\mathrm{R}_{1} \mathrm{D}_{2} ; \mathrm{R}_{1} \mathrm{D} 4 ; \mathrm{R}_{1} \mathrm{O}_{1}$. This is because decision makers (e.g. directors and 
owners) tend to heavily rely upon the effectiveness of problem solving process exercised by senior managers' experiences, particularly in planning and rough estimating, rather than BIM technologies. Regarding non-BIM specialists at lower level management (e.g. site engineers), BIM is perceived as simply $3 D$ visual representation to assist them with buildability issues. "3D models help site staffs with understanding complex MEP intersection settings. ”- $\mathrm{R}_{11-15} \mathrm{C}_{1}$. Site staffs expressed that their distrust of using BIM models for entire construction process is due to the corrupted data transmission and downtime problem. "We can't rely on the inaccuracy $3 D$ models for our consecutive scheduling analysis" and "It's impossible to create $4 D$ scheduling models as the speed of BIM tools were not full able to catch up the site progress." $-\mathrm{R}_{11-15} \mathrm{C}_{1}$. In addition, site staffs cannot fully engage in developing BIM models as their tasks are under the control of site managers. Information update for as-built models, hence, is likely either interrupted or inconsistent as the new decisions of personnel rotation and arrangement within and across projects are practiced frequently by site managers.

BIM as emerging skills for AEC professionals. The data disclosed that BIM has been still not recognized as a mainstream profession such as architecture and engineering. Currently, BIM is perceived as a new skillset (i.e. computer technology enhancement) necessary for AEC professionals rather than a new construction domain. This is because BIM philosophy of fully collaboration with all stakeholders relies on trust, collaboration and transparency which are all new in compared to the conventional approach. The Government agents asserted that their current intentions are to increase the awareness of BIM among industry by emphasizing the need for BIM education associated with universities and companies. "Considering BIM as a new discipline means the Government must revise most building codes and standards to support it- that are really exhausted tasks" - $\mathrm{R}_{1} \mathrm{G}_{1} ; \mathrm{R}_{2} \mathrm{G}_{1}$. Further, $\mathrm{BIM}$ is viewed as not much of relevance to construction business. Neither general contractors nor owners are satisfied with additional payment for BIM services. Contractors supposed that BIM skill sets help designers to increase the speed and accuracy of the designs but these benefits are not directly relevant to their bottom line. "We still make profits with traditional methods, just rework and raise extra-claims"- $\mathrm{R}_{2} \mathrm{C}_{1} ; \mathrm{R}_{3} \mathrm{C}_{1} ; \mathrm{R}_{4} \mathrm{C}_{1}$. For owners, their focus is seen as making quick profits by selling buildings faster. They may have to "build the units at lower cost to sell quickly rather than raise the standard of construction"'- $\mathrm{R}_{1} \mathrm{O}_{1}$. In other words, BIM is perceived as a tool (or skill set) to help project members (e.g. contractors) achieve their goals [8] but has been slow to change the owners' business models.

\section{Discussion}

The perception of job insecurity is influenced by the contextual conditions in Vietnam where BIM specialists feel unsecured about their roles. First, the copyright liability of BIM software could suspend BIM team's activities. The low morale and sensitivity to copyright violation could be explained by the Asian "collectivist culture" which leads to a weak individual assumption of responsibility- meaning "the rightness of a law decreases when more people violate it" [9]. Second, BIM specialists do not feel satisfied 
and happy with their malfunctioned BIM products as they insufficiently meet the expectations of other social members (e.g. peers and senior managers). This feeling matches the concept "structural equivalence" in social system of DOIT [4]- that is, the degree of equality in network position could influence the adoption of innovations [10].

The perception of depleted motivation coincides with the concept "interpersonal communication" of DOIT [4]- meaning that the effects of peer comparison and the lack of knowledge sharing network are critical barriers to higher BIM practices. Whereas, the perceptions of BIM as only a supporting role and BIM as new skill sets all come from the concept "perceived relative advantage of an innovation" in DOIT [4]- implying that although Vietnamese contractors and owners are actively engaged on gaining all possible outcomes and benefits out of BIM, they do not see any significant growth with just 3D. To these stakeholders, 3D model [even in BIM platform] is only as good as a paper-based blueprint, just that it is easier to interpret and explain.

Given the above perceptions on BIM profession, it is argued that at the individual level (e.g. single users and in-house usages), the diffusion and adoption of "basic" BIM technologies could be critical; whereas, at the industrial/project level (e.g. multi-disciplines and stakeholders involved), regulatory supports and diffusion networks could be more important. Policy makers should facilitate true collaboration [by regulatory supports] between disparate project stakeholders who are often reluctant to share innovative solutions due to contractual relationships and intellectual property issues. Copyright issue should be taken into account to enhance the development of local BIM software companies for more affordable BIM solutions. Also, the official recognition of $B I M$ as a mainstream AEC profession is necessary to reassure the roles of BIM specialists into companies and projects- helping BIM specialists with the more confident career path. Since contractors are eager to manage their onsite tasks, 4D BIM scheduling for optimal resource uses and manageable time-frame is recommended. Whereas, for owners, 5D BIM estimating for tracking cash-flow is on their top concern. Therefore, to ensure the digital transformation of the AEC industry happens, the long-term vision and commitment of senior industry officials to support higher BIM practices are necessary. Companies in the construction sector should develop a BIM knowledge network with professional institutions and university academics to be able to maintain additional channels of advice and support. Also, intra-organization BIM network could be developed with the leadership of key BIM diffusion drivers (e.g. top general contractors and developers) to feed updated BIM practice knowledge back into BIM projects.

\section{Conclusion}

This research identified key themes that cover common understandings of stakeholders regarding BIM profession relevant to their job/business. While the themes (job insecurity and depleted motivation) show the negative attitudes of BIM specialists towards the lack of "trust" environment for participative safety, the themes (BIM as supporting roles and BIM as emerging tools) present the "wait and see" attitudes of non-BIM specialists due to the lack of reliable sources for seeking higher levels of BIM solutions specific to their situations. The recommendations, hence, tend to shift the focus to the 
"network building" associated with regulatory supports rather than the "simply" mandatory submission of architectural models, and "basic" BIM education framework.

The recommendations may seem contradictory to the common diffusion approach (top-down processing) of generalizing basic [3D] BIM principles using "propaganda" from the Government-led curricula. Despite having certain benefits which are obviously realized and easily imitated (thus, raising awareness and faster diffusion); 3D BIM is still seen as "incremental" and "low-tech" innovation application compared to the full BIM exploitation. Further, industrial parties in Vietnam have come a long way in the last decade-evident by some advanced companies now advise on BIM implementation (radical practices) back to the "BIM lagging behind" Government; and the fact that the national BIM regulations, industrial standards and academic courses have not kept pace with innovative BIM practices. The industry innovation, hence, does not require to be generally educated but to be re-aligned (e.g. orientation, connection, and facilitation) for self-evolution. Building the strong peer-network sponsored by the Government and driven by industry leaders (bottom-up processing) appears to be the prominent solution and high-priority task in the case of resource shortage, low-tech infrastructure, and overwhelmed by policy changes- not only BIM standards/protocols but also relevant policies supporting sustainable BIM development such as ownership and intellectual property, contractual agreement, authenticity, product liabilities risks, incentives, etc. Also, the draft BIM legislation is easily put on the networks to get public feedback/comment for policy-revision and "already" mindset-preparation for change.

\section{References}

1. Mehran, D.: Exploring the adoption of BIM in the UAE construction industry for AEC firms. Procedia Engineering 145, 1110 - 1118 (2016).

2. Le, N., Er, M., Sankaran, S.: The implementation of Building Information Modelling (BIM) in construction industry: Case studies in Vietnam. International Journal of Engineering and Technology 10 (4), 335-340 (2018).

3. Le, N., Er, M., Sankaran, S.: Building Information Modeling (BIM) adoption and implementation: Interaction between BIM users and non-BIM users. In: 4th Australia and South-East Asia Structural Engineering and Construction Conference, pp. 1- 6. ISEC Press, USA (2018).

4. Rogers, M.: Diffusion of innovation. 5th edn. Free Press, NewYork (2003).

5. Ismail, N., Chiozzi , M., Drogemuller, R.: An overview of BIM uptake in Asian developing countries. In: 3rd International Conference on Construction and Building Engineering, pp. 1-7. AIP Publishing, USA (2017).

6. Walasek, D., Barszcz, A.: Analysis of the adoption rate of Building Information Modeling [BIM] and its return on investment [ROI]. Procedia Engineering 172, 1227-1234 (2017).

7. Yin, R.: Case study research: Design and methods. 3rd edn. Sage Publications, USA (2003).

8. Sistani, N., Rezaei, A.: Building Information Modeling; a new business trend in the construction industry of Iran. In: Achour, N. (eds.) CIB WORLD BUILDING CONGRESS 2016, vol.5, pp. 856 - 867. Tampere University of Technology Publishing, Finland (2016).

9. Wang, F.: Software piracy and ethical decision making behavior of Chinese consumers. Journal of Comparative International Management 8 (2), 43-56 (2005).

10. Valente, T.: Social network thresholds in the diffusion of innovation. Social Networks 18, 69- 89 (1996). 